\title{
AUTONOMY - A Flexible and Easy-to-Use Assistive System to Support the Independence of Handicapped and Elderly Persons
}

\author{
Christian Flachberger, Paul Panek, Wolfgang L. Zagler \\ fortec - Working Group on Rehabilitation-Engineering \\ Vienna University of Technology
}

\begin{abstract}
A new assistive system to support the independence of handicapped persons and elderly persons with handicaps is under development at the Working Group on Rehabilitation Engineering at the Vienna University of Technology. This paper describes the concept of the system. To meet the requirements of the very different possible users, high flexibility in supported functions and configuration of the user interface is essential for the concept. So this paper reports about a step towards an all purpose assistive system, usable by very different handicapped persons.
\end{abstract}

\section{Global Aspects}

\subsection{Some Statistical Remarks on the Situation in Austria and Central Europe}

i) According to estimations carried out by the Austrian Statistical Office (Österreichisches Statistisches Zentralamt) it can be expected that the relation between persons in need of care and caregivers will increase by the factor of two until the year 2030.

ii) Within this century the average age for entering employment has risen from 15 to 25 years; the average age for retirement has dropped. [9]

INTERPRETATION: The bottleneck in the field of professional caregiving is likely to become critical.

iii) More than $80 \%$ of the care provided in a western community is accomplished by relatives; only $20 \%$ is provided by professional care institutions.

INTERPRETATION: If the above mentioned bottleneck narrows down the importance of caregiving within the family will rise.

iv) Though, with respect to age, today more generations are alive simultaneously there is a tendency from the 3-Generation-Household to the 2-GenerationHousehold even to the 1-Person-Household.

INTERPRETATION: This trend is counterproductive to family provided care. 
RÉSUMÉ: This gap will, in the near future, lead to severe social problems which can only be solved by a wide holistic approach. This includes the development of ambulant and mobile services as well as the invigoration of family structures which are in the state of decay for most Central European countries because of changes in society and doubtful family politics.

One aspect of this holistic approach should be the implementation of up-to-date and ergonomic technical aids. At least in Austria there is a considerable gap left between available technologies and the development of the rehabilitation technology market. Many technologies are already existing in principle but are not available for those persons who would need to use them. This has been shown recently ([4], [5], [10]).

\subsection{The Family as Caregiver}

Within the population which is in need of care and which is nursed by relatives two trends are emerging:

i) Significant increase of elderly disabled persons due to the ageing of the entire population

ii) Increase of (multiply) disabled persons due to improved chances to survive critical situations caused by accidents, illness or complications during birth.

When it comes to caring for family members two major problems arise:

i) Staying at home vs. institutional care:

Persons in need of care suffer from the feeling to be a burden to their relatives. This is supported by the fact that on the one hand $95 \%$ of the population in need of care prefer living at home to institutional care but, on the other hand, are willing to live in an institution if the amount of care they need tends to increase.

ii) Burned-out-Syndrome of caregivers:

The Burned-out-Syndrome denotes a state of psychical exhaustion caused by permanent overload for the caregiver (the caring relative).

Both problems are stressing the social relations and are leading to a lower quality of life.

\section{The Role of Assistive Technology Systems (ATS)}

The above mentioned scenario leads to the following tasks and functions an Assistive Technology System (ATS) has to fulfil:

i) Persons in need of care should be able to use an ATS in the full sense of a compensatory device which will widen their abilities by using their residual functions. The extended activity range will lead to more independence and increasing quality of life. These aspects are covered by the environmental control functions of the ATS 
ii) Improved possibilities for communication (Telecommunication as well as person to person communications) widen the social range and increase the number of contact persons.

iii) Ensuring the personal security even in the absence of the caregiving person. This makes it possible that persons in need of care can stay alone from time to time.

Common to all three aspects is that they lead to more personal independence of the disabled or elderly person and to a reduction of the load placed on the carers [2]. This mutual relief creates a better climate for the development of interpersonal relations which, in this case, will not be undermined but fostered by the use of technology [8].

\section{The AUTONOMY Concept}

\subsection{System Requirements}

- Interaction with the system must be adaptable to the individual abilities of the user.

- The functions and specifications of the system must be adaptable to the individual requirements of the user [11].

- All assistive functions should be integrated in one single system and should be operated via a single user interface.

- Multiple handicapped persons with whatever combinations of disabilities should be supported.

- Elderly people should be accommodated by an user interface suited especially for aged persons.

- The system complexity should be variable within a wide range of individual needs.

- The system should be prepared for expansion and shrinking.

- Installing the system should require the minimum possible effort (e.g. by using wireless communication channels). So it can be used for short-time applications as well.

- The mobility of the user terminal should ensure comfortable operation for wheelchair users.

- The system should be equipped with a set of security features to warrant the safety of the user even in case of system misfunctions (error detection/correction, automatic restart, decentralized system supervision, automatically triggered emergency call in case of function breakdown). 


\subsection{Examples for AUTONOMY Basic Functions}

\section{i) Communication}

- Operating the telephone by severely disabled persons. The great importance of this function is shown in the study from M. Ferrario [7].

- Communication via symbol-languages (e.g. Bliss).

- Synthetic speech output for speech impaired persons.

- PC operation by adapted input devices. Thus, the user can access all features of modern information technology like text processing, databases, reading of books stored on CD-ROM, computer games etc.

\section{ii) Environmental Control (Remote Control)}

- Remote controlling of lighting, window blinds, air-condition [17] etc.

- Remote controlling of TV/video/HiFi-Equipment and other pieces of consumer electronics.

\section{iii) Safety Functions}

- Telephone with emergency call function

- Operating the intercom and the door-opener

- Dead-man's device

\subsection{Technical Realization}

System Structure. To cover these requirements in an optimal way the following system structure has been designed:

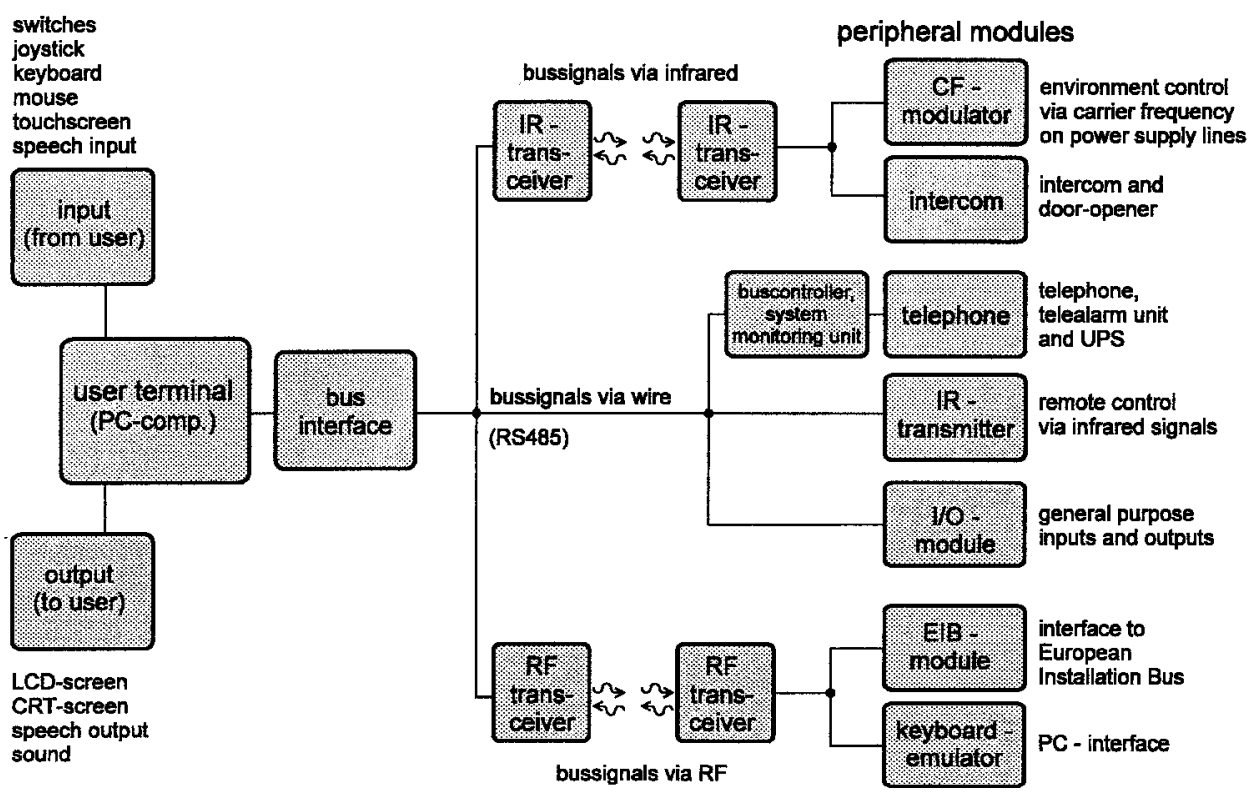

Fig. 1. Example for a system structure of AUTONOMY 
The system consists of a mobile user terminal which is linked to the peripheral modules by a bus system. The user terminal can be connected to input/output devices tailored to specific user needs (e.g. input devices [3] like special switches, joysticks, standard or modified keyboards, touchscreens and output devices like LCD or CRT screens, speech output or soundboards). The user terminal has to handle the entire interaction with the user. To ensure optimum adaptation to the user needs and abilities the software has to be highly flexible and must be variable by configuration in a wide range. For this reason the user terminal is made up by a PC-compatible microcomputer (e.g. embedded PC). The PC itself is concealed.

The various peripheral modules are responsible for carrying out certain functions and for linking to other systems. They can be considered as building blocks which can be combined according to the demand of the user. Functional transparency of these blocks is important, as shown in the work of I. Craig and P. Nisbet [6].

The link between the user terminal and the peripheral modules is established by a serial bus. Data transmission can be accomplished by wire (RS-485), via radio or infrared light - or by a combination of these means.

A watchdog feature is implemented in the user terminal. System errors are detected and cause the processor to reboot. In addition to this, the telephone-module which is responsible for emergency calls performs periodical system checks. A lasting and not amenable system break down is recognized by the telephone module in a decentralized manner and triggers an emergency call.

The Software Concept "AUTOSOFT". The flexibility of the AUTONOMY user interface also calls for a maximum of variability in the area of software. To reach this degree of flexibility the following strategy has been used:

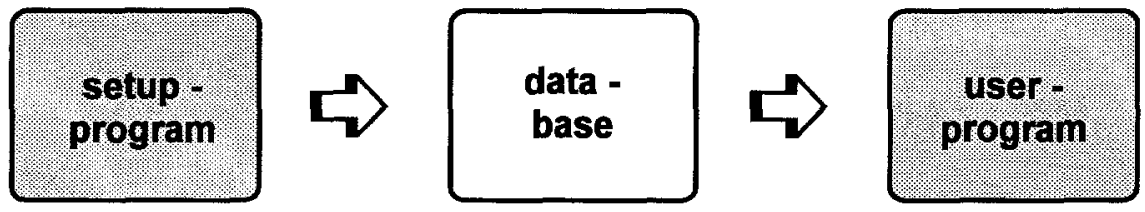

Fig. 2. The software concept "AUTOSOFT"

While A. Tronconi et al. distinguish two different phases in the utilisation of their system [16], we decided to distinguish two very different programs building up the AUTONOMY-System.

The essential program for establishing the user interface is hardcoded but imports all information about the composition of the user interface, about the functions to be supported etc. from an extensive data base.

This data base is set up and modified by using a configuration program. Implemented in the configuration program there is a test-mode by which the system operation can be simulated. This allows for immediate testing of a configuration without leaving the configuration program.

Nevertheless, modifications of global parameters like the timing of input devices can also be accomplished during the execution of the user program. 
Menues and Icons. The basic structure of the user interface is composed of a number of hierarchical menues. These menues are defined during the configuration procedure (using the configuration program) and filled with functional elements. Every functional element consists of a part defining the user interaction (a graphical symbol, a piece of text, a phrase to be spoken by the synthesizer etc.) and a second part determining a function (execution of a list of commands, moving to another menue etc.). As the functional elements are mainly represented by their graphical symbol on the screen they will be called icons even if their manifold features reach far beyond the characteristics of usual icons (graphic symbol assigned to a certain function).

Structure of an icon:

- name

- graphic symbol

- text beneath the graphic symbol

- function (list of commands to be executed)

- speech pattern (for the speech recognition system) *)

- piece of prerecorded speech *)

- piece of text for the speech synthesizer ${ }^{*}$ )

*) options

Functions. The functions are assigned to an icon as a list of commands. During the configuration all commands to be executed by activating the icon are entered into this list (e.g. "increase TV volume", "telephone off-hook", "open door", "move to another menue"). The link between the commands (which are entered as plain text) and the codes necessary to address and activate the peripheral modules is accomplished via a special command file.
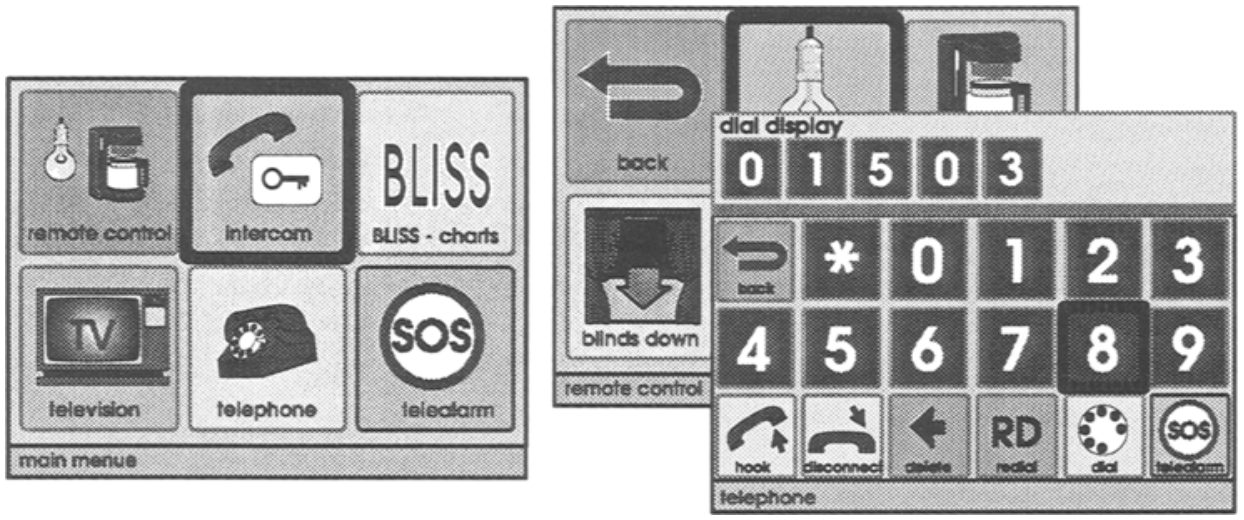

Fig. 3. Some examples for user specific screen menues of autonomy 
Events. Events are things that happen in the periphery and which are reported to the user terminal (e.g. "The telephone is ringing"). Similar to the icons the reaction of the system to the occurring of an event can be defined by a command list. The advantage of this concept is that functional links can be established. For example: If the telephone is ringing the system can automatically display the menue necessary for operating the telephone; at the same moment the volume of all sound sources (TV, HiFi) will be reduced to a level not disturbing the telephone conversation. This will, in some cases, lead to significant time savings for the user.

The versatility of the "AUTOSOFT"-Concept. The versatility of the "AUTOSOFT"-concept can best be demonstrated by the following examples:

Example 1: Environmental Control (remote control). Within one single menue remote control functions for different devices using different transmission channels can be combined at will. For consumer electronic products remote controls reduced to the essential functions can be realised.

Example 2: Telephone control. In addition to the icons for functions like "hook", "dial" etc. any number of direct-dialling keys or even an extensive telephone directory can be installed where the command to dial a certain number is assigned to the corresponding icon.

Example 3: Picture communication (symbolic communication). The concept of icons perfectly supports picture communication. During the configuration step words or phrases are assigned to appropriate icons (e.g. using Bliss symbols). In order to be able to compile longer sequences of text and to edit this text before activating the speech output, the configuration of any icon allows options for immediate execution of the commands or storing the icon in an editor.

It should be mentioned that even a combination of symbols for picture communication with telephone operation is possible. By this means persons who are both, mobility and speech impaired, can get access to the telephone.

Example 4: Simulating a PC keyboard and a mouse. Part of the AUTONOMYSystem is a peripheral module which emulates the PC keyboard and the mouse. By assigning commands for the simulation of keystrokes to certain icons AUTONOMY can be used to access any PC. As the keyboard/mouse emulation is accomplished by external hardware, problems with compatibility are a priori eliminated.

\section{Special Aspects of the AUTONOMY System}

\subsection{Ergonomy and different levels of users}

One of the main goals of the AUTONOMY project is the creation of a system with a maximum of ergonomic design in order to cover the very heterogeneous needs of the 
users (according to [11], [14], [1]). To achieve optimum adaptation to individual user needs the AUTONOMY system offers a variety of possible configurations for the user interface and the user program.

From interviews with prospective users of the future system it became evident for the project team that the ergonomy of the configuration program is a prerequisite for the ergonomy of the user program

The AUTONOMY system distinguishes (with reference to the work of Dag Svanæs et al. [15]) three groups of users:

- Level 1 users (L1U): Persons with special needs

- Level 2 users (L2U): Therapists, family members etc.

- Level 3 users (L3U): Experts, installers

The L1U is the end-user of the system which has been tailored to his/her personal needs and abilities. The L2U has a profound knowledge about the L1U's needs and abilities and is ready to work out a configuration which as much as possible fits the requirements. For setting up the configuration data he/she will use the configuration program. The role of the L3U is the initial installing of an AUTONOMY system in a way which enables the L2U to perform the individual adaptations without in-depth knowledge.

The L2U is supported by the configuration program which offers a MS-Windowslike intuitive user interface. Furthermore the present system configuration is graphically displayed for on-line testing of possible variations. It is assumed that the L2U because of his/her importance in configuration optimization will play an essential role concerning the user acceptance of the entire system.

\subsection{Multiple handicaps}

AUTONOMY will offer assistance for different types of functional impairments:

- Visually impaired persons: Persons with low vision will profit from the variable icon size (the number of icons to be displayed can be selected). In extreme cases only one single icon will be displayed on the entire screen. For blind persons an acoustic user interface can be configured. The names of the selectable icons will be announced by speech synthesis.

- Mentally retarded persons: They will use simplified procedures. For example a telephone call can be established by selecting an icon showing a photography of the person to be called without the necessity of knowing any details of operating a telephone.

- Persons suffering from dementia: Persons whose abilities are tending to decrease will profit from the system's flexibility. The system not only can be expanded to meet increasing needs or abilities, if necessary, a shrinking is also possible.

- Persons with speech impairments: They will use the speech output (text to speech synthesis or digitally recorded speech) for communication.

- Persons with language impairments: They will be assisted by the implementation of BLISS-Symbols. 
- Persons with motor impairments: They will be offered various methods to control the AUTONOMY-System with a single switch and so on.

In case of multiple handicaps more than one of these functions can be implemented at once into the system.

\subsection{System logbook and evaluation}

All system-user interactions as well as other events which occur during the use of the system can be recorded. The evaluation of these recordings can offer valuable information for:

- the therapist about possible optimisation of the personal system configuration and about therapeutical progress achieved by using the system (progress in training).

- the system engineer about the acceptance of the implemented user interface during real application.

- the scientist to gain new knowledge about user interface design for persons with special needs.

- the technician for eliminating weak elements of the system during test applications (recording the history preceding system failures).

The logbook-recording is a background job which does not show up on the common user interface. It goes without saying that activating the logbook-function must be agreed upon with the L1U.

\section{Future Aspects}

Presently the here described assistive system called "AUTONOMY" is under development by the Working Group on Rehabilitation Engineering at the Vienna University of Technology. One of the next steps will be the manufacturing of several prototypes and the evaluation of the entire system. A co-operation with a support centre for physically and multiple handicapped persons is planned.

In care giving and rehabilitation the classical goals "warm", "well fed" and "clean" are superseded by the goal of helping the person in question to regain or keep a maximum of independence. Assistive technology has to fit into this concept. Thus the implementation of assistive technology like AUTONOMY must be part of the therapeutical program and must not be done in isolation. Only if therapy, medical treatment, social environment, barrier-free design and assistive technology work together in an optimum way comprehensive care and rehabilitation will be successful. This fact has been shown by Marcia L. Scherer in the "Matching Person and Technology (MPT) Model", described in [13].

Besides evaluating the concept of "AUTONOMY" in ergonomic, technical and social manners, one goal will be the development of a model for an all-embracing program of rehabilitation based on a holistic approach including assistive technology. This will be done in co-operation with the support centre for physically and multiple handicapped persons and its experts (e. g. occupational therapists). 


\section{References}

1. Baeyens, J.P.: Introduction to and Summary on (Home) Health Care (Technology), in: Bouma, H. and Graafmans, J.A.M. (Eds.): Gerontechnology, Amsterdam: IOS-Press, 1992, 395-399.

2. Bogman, J.A.M.: The Application of (Innovative) Technology in the Care for and Service to the Elderly and the Disabled, in: Bouma, $H$. and Graafmans, J.A.M. (Eds.): Gerontechnology, Amsterdam: IOS-Press, 1992, 367-371.

3. Brandt, Åse: Control of Computers for People with Physical Disabilities, in: Zagler, W. (Ed.): Proceedings of the 3rd International Conference on Computers for Handicapped Persons, Vienna: Oldenbourg, 1992, 71-76.

4. Brandt, Å.; Seelen, B.; Biilmann, Z.: Why don't hospitals use electronic communication aids for patients who are severely motor impaired and who can't speak?, in: Proceedings of the Second European Conference on the Advancement of Rehabilitation Technology, Stockholm: Swedish Handicap Institute, ECART, 1993, p.1.3.

5. Carruthers, St.; Humphreys, A.; Sandhu, J.: The Market for R.T. in Europe: a Demographic Study of Need, in: Ballabio, E.; Placencia-Porrero, I.; Puig de la Bellacasa, R. (Eds.): Proceedings of the 1st TIDE Congress (Technology for the socio-economic Integration of Disabled and Elderly people), Amsterdam: IOS-Press, 1993, 158-163.

6. Craig, Ian and Nisbet, Paul: The smart Wheelchair: An augmentative Mobility 'Toolkit', in: Proceedings of the Second European Conference on the Advancement of Rehabilitation Technology, Stockholm: Swedish Handicap Institute, 1993, p.13.1.

7. Ferrario, Massimo: Experimentation for a counselling, personalizzation and training aids and technical devices for a personal and / or housing autonomy for quadriplegic people, in: Proceedings of the First European Conference on the Advancement of Rehabilitation Technology, Hoensbroek, The Netherlands: ECART, 1990, p.6.1.

8. Helle, Kari Marie and Tiller, Hanne: Needs of the disabled and solutions by computer technology including human, social and financial aspects, in: Tjoa, A.M.; Wagner, R; Zagler, W. (Eds.): Proceedings of the Second International Conference on Computers for Handicapped Persons, Vienna: Oldenbourg, 1990, p.123-128.

9. Lehr, Ursula: Langlebigkeit verpflichtet zur Prävention und Rehabilitation, Vortrag gehalten im Zuge der Rehabilitations-Herbsttagung, Tiroler Verein zur Förderung sozialmedizinischer Betreuung und Rehabilitation, Innsbruck, Oktober 1993 
10. Martin, M.: People with Special Needs as a Market, in: Tetzcher, St.v. (Ed.): Issues in Telecommunication and Disability, Luxembourg: COST 219, Commission of the European Communities, 1991, p.55-60.

11. Read, R.F: Client Evaluation and Equipment Prescription, in: H. Murphy (Ed.), Proceedings of the Fifth Annual Conference: Technology and Persons with Disabilities, Los Angeles: Office of Disabled Student Services, California State University, Northridge, USA, 1990, 553-564.

12. Read, R.F.: Technology Delivery is a Technology, in: H. Murphy (Ed.), Proceedings of the Fifth Annual Conference: Technology and Persons with Disabilities, Los Angeles: Office of Disabled Student Services, California State University, Northridge, USA, 1990, pp. 565-578.

13. Scherer, M.J.: Living in the State of Stuck - How Technology Impacts the Lives of People with Disabilites, Cambridge, MA: Brookline Books, 1993.

14. Stewart, Tom: Physical Interfaces or "Obviously it's for the Elderly, it's grey, boring and dull", in: Bouma, H. and Graafmans, J.A.M. (Eds.): Gerontechnology, Amsterdam: IOS-Press, 1992, 197-207.

15. Svanæs, D.; Lundälv, M.; Poon, P.: The Specification of a Versatile Communication Aid and Writing Tool, in: Proceedings of the Second European Conference on the Advancement of Rehabilitation Technology, Stockholm: Swedish Handicap Institute, ECART 1993, p.P.III.

16. Tronconi, A.; Tronconi, R.; Billi, M.; Stefani,L.; Focardi, F.: A Multimedia Communication System for Severe Physically Disabled People, in: Proceedings of the Second European Conference on the Advancement of Rehabilitation Technology, Stockholm: Swedish Handicap Institute, ECART 1993, p.P.III.

17. Zegers, L.E.: Integrated Applications for the Home, in: Zegers, L.E. (Ed.): Home Systems, Proceedings of the European Conference on Integrated Home Applications, Amsterdam: RAI Congress Centre, 1991, p.1.1-7.

The project "autonomy" is going on in co-operation with Legrand Österreich Ges.m.b.H. 